\title{
CHALLENGES IN EVALUATING THE LEARNING EXPERIENCE WITH NOVEL TECHNOLOGIES
}

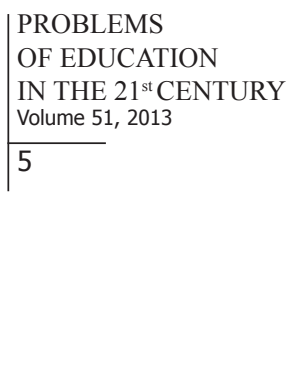

PROBLEMS

IN THE $21^{\text {st }}$ CENTURY

Volume 51, 2013

Costin Pribeanu

ICI Bucharest, Romania

E-mail: Pribeanu@ici.ro

The shift towards constructivism in e-learning creates new opportunities in the modern school and favors the introducing of novel technologies able to promote a learner-centered approach and increase the students' motivation to learn. Augmented reality (AR) is such a novel technology that promotes a new learning experience by integrating real objects, familiar from the traditional class, into a computing environment. AR has many valuable features from both the teacher's and learner's perspective: $3 \mathrm{D}$ visualization of complex processes, animation, multimodal interaction with real objects (visual, auditory and haptic), and augmentation. In turn, these features create various learning affordances such as: spatial ability, support to memory cognitive processes, experiential learning, collaboration, and motivation (di Serio, Ibanez \& Kloos, 2012).

In general, novel technologies are expensive and the costs are not only related to the hardware and software platform. The implementation in the traditional school requires additional costs for maintenance, content development, and training. Therefore, the first key concern when evaluating such e-learning systems is to capture the added value brought in by the novel technology. This means to go beyond the pedagogical evaluation and to evaluate the paradigm against some control condition. For example, it might be possible that a given technology works well only for some disciplines but brings no or little added value to others. If we go into more detail, the paradigm could work well only for some lessons which focus on the understanding of key concepts. In this case, the implementation would be more appropriate for a laboratory setting than for a class setting. For example, AR proved to be useful in understanding the Chemical structure of the atoms, Chemical bonds, and Chemical reactions. The added value also varies according to the target user population: a given technology may be appealing for young learners in primary school but boring for students in secondary school.

The second key concern is the usability of a novel technology. The ISO standard 9241210:2010 defined usability as the extent to which a product can be used by specified users to achieve specified goals with effectiveness, efficiency and satisfaction in a specified context of use. Designing the usability is not an easy task in emerging technologies like AR and VR systems, where a lot of resources are spent with 3D visualization features and too little attention is paid to the usability of interaction techniques. Usability problems may seriously affect both the perceived usefulness and perceived enjoyment. A special attention should be paid to the usability of interaction techniques that imply the manipulation of real objects: if not usable enough this might undermine the acceptability of the whole system.

The third key concern is the acceptability of a new system. The evaluation of technology acceptance requires a quantitative approach based on larger models that include several factors, such as: characteristics of the system, perceived ease of use, perceived usefulness, relevant social aspects, and perceived enjoyment. A problem is the target user: most studies in the elearning domain are only based on students' perception. This is mainly because quantitative methods require a minimum sample size which is easier to collect from students. However, the teachers' opinions are also important as well as the opinion of managers which finally decide if it is worth to adopt a novel technology. 
PROBLEMS

OF EDUCATION

IN THE $21^{\text {st }}$ CENTURY Volume 51,2013

The learning experience is the user experience with an e-learning system. The ISO standard 9241-210:2010 defined the user experience as a person's perceptions and responses that result from the use and/or anticipated use of a product, system, or service. User experience (UX) evaluation goes beyond the traditional usability evaluation which is mainly concerned with the effectiveness, efficiency and satisfaction of a user that performs specified tasks in a specified context of use. UX is also related to the hedonic aspects of using the technology. An enjoyable learning experience is increasing the students' motivation to learn. In the previous work we showed that the intention to use an AR teaching platform depends on both its perceived usefulness and perceived enjoyment (Balog \& Pribeanu, 2010).

User experience is a hot field of research that developed rapidly in the last decade. In the recent work, Vermeeren et al. (2010) highlighted several challenges for UX research, among which we could mention: providing and validating measures for different UX foci and domains, providing methods for UX evaluation in collaborative work, need for more effective multimethod approaches (which methods work well together). These challenges are quite relevant when evaluating how new technologies could positively impact the e-learning systems.

Providing valid measures for different UX foci in the e-learning domain is not easy. There are relatively few studies that analyze the various facets of the hedonic quality and how each of them is increasing the motivation to learn. There are also several questions to answer. To which extent learning activities should be enjoyable? Which are the features of a novel technology that students mostly wish? Which are the attributes that better support the learner's engagement: interesting, captivating, funny? Which are the most suitable measures of enjoyment in each educational cycle?

Regarding the methodology for UX evaluation, several issues arise. Traditionally, approaches to evaluation are related to either a quantitative or a qualitative paradigm. In this respect, mixed methods research is a new paradigm that recently gained considerable attention in various application domains such as information systems, social and behavioral sciences. Mixed methods approaches combine quantitative and qualitative methods in order to increase the confidence in results and get a deeper understanding of specific aspects. Analysis of qualitative data may reveal many factors that were not taken into consideration in a quantitative model. Conversely, qualitative methods could bring valuable insights and enrich the description of phenomena captured by a quantitative method.

\section{References}

Balog, A., Pribeanu, C. (2010). The role of perceived enjoyment in the students' acceptance of an AR teaching platform: A structural equation modeling approach. Studies in Informatics and Control, 19 (3), 319-330.

Di Serio, A., Ibáñez, M. B., Kloos, C. D. (2012). Impact of an augmented reality system on students' motivation for a visual art course. Computers \& Education Journal, 1-11.

Vermeeren, A., Law, E. L. C., Roto, V., Obrist, M., Hoonhout, J., Vaananen-Vainio-Mattila, K. (2010). User Experience Evaluation Methods: Current State and Development Needs. Proc. NordiCHI 2012, 521-530.

Received: March 08, 2013

Accepted: March 12, 2013

Costin Pribeanu

$\mathrm{PhD}$, Senior Researcher I, National Institute for Research and Development in Informatics - ICl Bucharest, Bd. Maresal Averescu nr. 8-10, 011455, Bucharest, Romania.

E-mail: pribeanu@ici.ro

Website: http://rochi.ici.ro/pribeanu/ 